\title{
Lewis Acid Catalyzed Reaction of Aromatic Vinyl Halides with Aromatic Aldehydes: A Novel Aldol-type Condensation Mimic
}

\author{
Philip W. H. Chan, Shin Kamijo, Yoshinori Yamamoto* \\ Department of Chemistry, Graduate School of Science, Tohoku University, Sendai 980-8578, Japan \\ Fax +81-22-217-6784; E-mail: yoshi@yamamoto1.chem.tohoku.ac.jp \\ Received 12 January 2001
}

\begin{abstract}
In the presence of catalytic amounts of Lewis acid, aromatic $\alpha$-vinyl halides readily undergo reaction with aromatic aldehydes at ambient temperatures to give a variety of substituted transchalcones in moderate to excellent yields. These compounds are potentially useful synthetic intermediates for organic synthesis as well as compounds of significance in terms of their ability to exhibit a wide spectrum of biological activity. This is the first reported example in which haloalkenyl derivatives other than metallooxyalkenes can participate in the Mukaiyama-aldol type carbon-carbon formation reaction.
\end{abstract}

Key words: Lewis acid, catalysis, $\alpha$-halostyrenes, aromatic aldehydes, substituted trans-chalcones

The emergence of the Mukaiyama-aldol protocol over the latter part of the $20^{\text {th }}$ century has established the aldol reaction as one of the most powerful tools in organic synthesis. ${ }^{1}$ Relying on the use of Lewis acid catalyzed metal generated enol ether nucleophiles, the ability to furnish important synthetic intermediates and target compounds in an expedient and stereoselective manner has played a significant role in its rise to prominence. To date, much attention within this field has primarily focused upon the development of this particular aspect of the reaction with the view of optimizing yields and stereoselectivity. In studies directed towards exploring the possibility of related reactions, we report herein a novel aldol-type condensation mimic. This involved a variety of aromatic vinyl halides and aldehydes to readily undergo reaction when subjected to catalytic amounts of Lewis acid at ambient temperatures to give the corresponding diaryl propenones in moderate to excellent yields. ${ }^{2}$ This new one step carbon-carbon bond formation procedure not only delivers potentially useful synthetic intermediates for organic syn- thesis but also provides ease of access to a class of compounds known to exhibit antibacterial, antiviral, gastric protectant, antimutagenic, retinoid, antimitotic and antiinflammatory activities in their own right. ${ }^{3}$

The reaction between $\alpha$-bromostyrene $1 \mathrm{a}$ and benzaldehyde $\mathbf{2 a}$ was initially chosen to establish the optimum temperature, solvent and catalyst conditions (Scheme 1 and Table 1). Thus, whilst pleased that the reaction proceeded smoothly at high temperature in the absence of both a catalyst and solvent to give trans-chalcone $\mathbf{4} \mathbf{a}^{4}$ in good yield (entry 1), it gave us greater satisfaction to achieve similar results at room temperature in a few cases with the introduction of a variety of stiochiometric amounts of Lewis acid catalysts in $\mathrm{CH}_{2} \mathrm{Cl}_{2}$ (entries 2-10). Under these applied conditions optimum yields were obtained when the reaction was carried out with $\mathrm{BF}_{3} \cdot \mathrm{Et}_{2} \mathrm{O}$ (entry 4).

With the catalyst of choice established, a variety of solvents were surveyed to establish the influence of the reaction medium on yield. In comparing the yield obtained for the model study carried out in $\mathrm{CH}_{2} \mathrm{Cl}_{2}$ (entry 4), the use of relatively less polar solvents furnished $\mathbf{4 a}$ in moderately lower yields (entries 11, 12). As for solvents of relatively higher polarity, with the exception of MeCN (entry 13), either trace product formation was observed or no reaction was detected (entries 14, 15). In contrast, optimum yields were obtained when the reaction was carried out in the absence of solvent with the reaction requiring only a catalytic amount of $\mathrm{BF}_{3} \cdot \mathrm{Et}_{2} \mathrm{O}(20 \mathrm{~mol} \%)$. Under these conditions, a mixture of the $\beta$-halo ketone intermediate $3 \mathbf{a}^{5}$ and $\mathbf{4 a}$ in $19 \%$ and $66 \%$ yield respectively was obtained with the former readily converting to $\mathbf{4 a}$ upon purification (entry $16){ }^{6}$

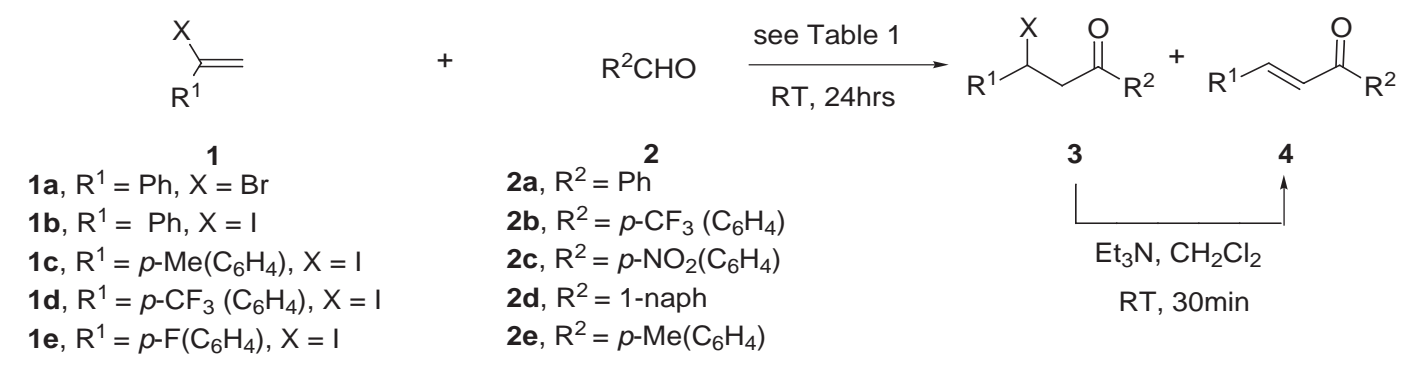

Scheme 1

Synlett 2001, SI, 910-913 ISSN 0936-5214 @ Thieme Stuttgart · New York 
Table 1 The Reaction of $\alpha$-Bromostyrene 1a with Benzaldehyde 2a under Various Conditions

\begin{tabular}{cccc}
\hline Entry & $\begin{array}{c}\text { Solvent } \\
(1 \mathrm{M})\end{array}$ & Lewis Acid & $\begin{array}{c}\text { Yield/\% } \\
4 \mathbf{a}\end{array}$ \\
\hline 1 & $-^{\mathrm{b}}$ & - & $70^{\mathrm{c}}$ \\
2 & $\mathrm{CH}_{2} \mathrm{Cl}_{2}$ & $\mathrm{ZnCl}_{2}{ }^{\mathrm{d}}$ & 66 \\
3 & $\mathrm{CH}_{2} \mathrm{Cl}_{2}$ & $\mathrm{HfCl}_{4}{ }^{\mathrm{d}}$ & 72 \\
4 & $\mathrm{CH}_{2} \mathrm{Cl}_{2}$ & $\mathrm{BF}_{3} \cdot \mathrm{Et}_{2} \mathrm{O}^{\mathrm{d}}$ & $73(72)^{\mathrm{e}}$ \\
5 & $\mathrm{CH}_{2} \mathrm{Cl}_{2}$ & $\mathrm{InCl}_{3}{ }^{\mathrm{d}}$ & trace \\
6 & $\mathrm{CH}_{2} \mathrm{Cl}_{2}$ & $\mathrm{SnCl}_{4}{ }^{\mathrm{d}}$ & decomposition \\
7 & $\mathrm{CH}_{2} \mathrm{Cl}_{2}$ & $\mathrm{AlCl}_{3}{ }^{\mathrm{d}}$ & decomposition \\
8 & $\mathrm{CH}_{2} \mathrm{Cl}_{2}$ & $\mathrm{ZrCl}_{{ }^{d}}$ & decomposition \\
9 & $\mathrm{CH}_{2} \mathrm{Cl}_{2}$ & $\mathrm{TiCl}_{4}{ }^{\mathrm{d}}$ & decomposition \\
10 & $\mathrm{CH}_{2} \mathrm{Cl}_{2}$ & $\mathrm{NiCl}_{2}{ }^{\mathrm{d}}$ & no reaction \\
11 & toluene & $\mathrm{BF}_{3} \cdot \mathrm{Et}_{2} \mathrm{O}^{\mathrm{d}}$ & 50 \\
12 & hexane & $\mathrm{BF}_{3} \cdot \mathrm{Et}_{2} \mathrm{O}^{\mathrm{d}}$ & 53 \\
13 & $\mathrm{MeCN}_{13}$ & $\mathrm{BF}_{3} \cdot \mathrm{Et}_{2} \mathrm{O}^{\mathrm{d}}$ & 40 \\
14 & $\mathrm{EtOH}$ & $\mathrm{BF}_{3} \cdot \mathrm{Et}_{2} \mathrm{O}^{\mathrm{d}}$ & trace \\
15 & $\mathrm{DMF}$ & $\mathrm{BF}_{3} \cdot \mathrm{Et}_{2} \mathrm{O}^{\mathrm{d}}$ & no reaction \\
16 & - & $\mathrm{BF}_{3} \cdot \mathrm{Et}_{2} \mathrm{O}^{\mathrm{d}}$ & $66^{\mathrm{f}}$ \\
\hline
\end{tabular}

${ }^{\mathrm{a}} \mathrm{GC}$ yields.

${ }^{\mathrm{b}}$ Carried out at $120^{\circ} \mathrm{C}$ for $24 \mathrm{~h}$.

'Isolated yield.

${ }^{\mathrm{d}} 1$ molar equivalent.

e 0.2 molar equivalent.

f $3 \mathbf{a}$ was also obtained in $19 \%$ yield.

The generality of the present novel reaction was next investigated. In employing either $\mathrm{CH}_{2} \mathrm{Cl}_{2}$ or solvent-free conditions in the presence of a catalytic amount of $\mathrm{BF}_{3} \cdot \mathrm{Et}_{2} \mathrm{O}(20 \mathrm{~mol} \%)$, a variety of other aromatic vinyl halides $\mathbf{1}$ and aldehydes $\mathbf{2}$ proceeded in a similar manner to give the corresponding product(s) $\mathbf{3}$ and $\mathbf{4}$ in moderate to excellent yields (Table 2). Reaction of $\alpha$-iodostyrene $\mathbf{1 b}^{7}$ with benzaldehyde $\mathbf{2 a}$, for example, afforded trans-chalcone 4a exclusively as the sole product in $84 \%$ yield (entry 1). Similarly, the reaction of $1 \mathbf{a}$ with aromatic aldehydes bearing electron withdrawing groups (EWG) afforded mixtures of the corresponding products $\mathbf{3 b}$ and $\mathbf{4 b}$, and $\mathbf{3 c}$ and $\mathbf{4 c}$ in excellent overall yields (entries 2-3). In both cases, the conversion of the former to the latter was readily achieved in quantative yields on addition of $\mathrm{Et}_{3} \mathrm{~N}$. In comparison, the reaction of $\mathbf{1 a}$ with aromatic aldehydes bearing electron donating groups (EDG) proceeded to give the corresponding adducts $4 \mathbf{d}$ and $4 \mathbf{e}$ in only moderate to good yields (entries 4-5). Conversely, the opposite was observed for reactions of a variety of aromatic vinyl halides bearing either EDG or EWG with benzaldehyde $\mathbf{2 a}$. Thus, in the case of reaction of $\mathbf{1 c}$ bearing a methyl EDG with $\mathbf{2} \mathbf{a}$, the corresponding adduct $\mathbf{4 f}$ was furnished in $61 \%$ yield despite its relative instability under acidic conditions (entry 6). In contrast, the analogous reaction of $\mathbf{2 a}$ with 1e bearing an F EWG gave $\mathbf{4 h}$ in only $44 \%$ yield whilst reaction of $\mathbf{2 a}$ with $\mathbf{1 d}$ bearing an even stronger EWG in the form of $\mathrm{CF}_{3}$ gave no reaction (entries 7,8).

In an attempt to understand the mechanism of our novel vinyl halide-aldehyde protocol, the reaction of 1c with benzaldehyde- $d^{8}$ was undertaken to give the deuterated product $4 \mathbf{i}$ in $21 \%$ yield (Scheme 2 ). ${ }^{1} \mathrm{H}$ NMR spectroscopic analysis of $\mathbf{4 i}$ enabled its $d$-content to be determined to be nearly $100 \%$. This was achieved by observing

Table 2 The Reaction of a Variety of Substituted Aromatic Vinyl Halides 1 and Aldehydes 2

\begin{tabular}{|c|c|c|c|c|}
\hline Entry & $\begin{array}{c}\text { Vinyl } \\
\text { halide } 1\end{array}$ & Aldehyde $\mathbf{2}$ & Product(s) 3:6 & $\begin{array}{l}\text { Yield } \\
\mathbf{3 : 4} \% \\
\end{array}$ \\
\hline 1 & $1 b$ & $2 \mathbf{a}$ & $4 a$ & 84 \\
\hline 2 & $1 a$ & $2 b$ & & $22: 72$ \\
\hline 3 & $1 b$ & $2 c^{a}$ & & $20: 57$ \\
\hline 4 & $1 \mathrm{~b}$ & $2 d^{a}$ & & 58 \\
\hline 5 & $1 \mathrm{~b}$ & $2 \mathrm{e}^{\mathrm{a}}$ & & 34 \\
\hline 6 & $1 c^{7}$ & $2 a^{b}$ & & 61 \\
\hline 7 & $\mathbf{1 d}^{7}$ & $2 a$ & & $n r^{c}$ \\
\hline 8 & $1 e^{7}$ & $2 a^{a}$ & & 44 \\
\hline
\end{tabular}

a Used as a $1 \mathrm{M}$ solution in $\mathrm{CH}_{2} \mathrm{Cl}_{2}$.

${ }^{b}$ Used as a $2 \mathrm{M}$ solution in $\mathrm{CH}_{2} \mathrm{Cl}_{2}$.

${ }^{\mathrm{c}} \mathrm{No}$ reaction under a variety of conditions. 


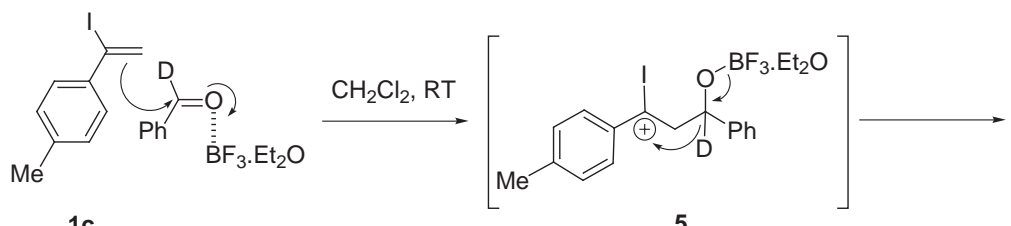

$1 c$<smiles>[2H]/C(=C\C(=O)c1ccccc1)c1ccc(C)cc1</smiles>

Scheme 2

the complete absence of the $A B$ system in $\mathbf{4} \mathbf{i}$, as seen to be present in its non-deuterated analogous adduct $\mathbf{4 f},{ }^{9}$ along with the replacement of this splitting pattern with a singlet signal at 87.52 . More significantly, this analysis also strongly implied the most probable involvement of an exclusively intramolecular hydrogen transfer step at some point in the reaction mechanism..$^{10}$ Consequently, on the basis of this data, we reasoned that the mechanism of our present reaction proceeded via the cationic intermediate $\mathbf{5}$ generated from the initial 1,2-addition of the vinyl halide $\mathbf{1}$ to the aldehyde 2 . Preferential intramolecular rearrangement of this reactive intermediate in the form of a 1,3-hydride shift then furnished the more stable $\beta$-halo ketone $\mathbf{3}$. The isolation of $\mathbf{3}$ (Table 1, entry 16 and Table 2, entries 2-3) in a few cases, in turn, augmented the credibility of our proposed mechanism. The $\alpha, \beta$-unsaturated carbonyl product $\mathbf{4}$ is then finally afforded upon subsequent hydrogen halide elimination, the rate of which is further enhanced when exposed to basic conditions (Scheme 2).

In order to determine the structure of the product unambiguously, the ozonolysis of $\mathbf{4 b}$ was carried out under standard conditions (Scheme 3). As anticipated, in obtaining benzaldehye 2a as the sole product, this result also confirmed the structure of the aldol-type product.

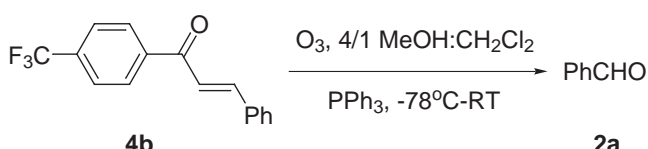

Scheme 3

In conclusion, we have demonstrated a novel aldol-type condensation mimic that allows access to a variety of substituted diaryl $\alpha$-halopropanones $\mathbf{3}$ and biologically active trans-chalcones 4 based on the facile Lewis acid mediated reaction of aromatic vinyl halides with aldehydes at ambient temperatures. We have also provided strong experimental evidence to propose a plausible reaction mechanism for this new transformation. Although the scope of the present novel reaction is limited to aromatic derivatives at the present stage, this is the first reported example in which alkenyl derivatives other than metallooxyalkenes can participate in the Mukaiyama-aldol type carboncarbon formation reaction.

\section{Acknowledgement}

This work was partially financially supported by a Grant-in-Aid for Scientific Research from the Ministry of Education, Science and Culture of Japan.

\section{References and Notes}

(1) For general reviews see: (a). Heathcock, C. H. In Comprehensive Organic Synthesis, (Eds.: Trost. B. M.; Fleming, I.), Pergamon Press, Oxford 1991, Vol. 2, pp 133179, 181-238. (b). Moon Kim, B.; Williams S. F.; Masamune, S. In Comprehensive Organic Synthesis, (Eds.: Trost. B. M.; Fleming, I.), Pergamon Press, Oxford 1991, Vol. 2, pp 239275. (c). Paterson, I. In Comprehensive Organic Synthesis, (Eds.: Trost. B. M.; Fleming, I.), Pergamon Press, Oxford 1991, Vol. 2, pp 301-319. (d). Gennari, C. In Comprehensive Organic Synthesis, (Eds.: Trost. B. M.; Fleming, I.),

Pergamon Press, Oxford 1991, Vol. 2, pp 629-660. (e). Braun, M. In Stereoselective Synthesis (Houben-Weyl, Methods of Organic Chemistry), (Eds.: Helmchen, G.; Hoffmann, R. W.; Mulzer J.; Schaumann, E.), George Thieme Verlag, Stuttgart 1995, Vol. E21b, pp 1603-1666, 1713-1735. (f). Franklin A. S.; Paterson, I. Contemp. Org. Syn. 1994, 1, 317-338. (g). Mahrwald, R. Chem. Rev. 1999; 99, 1095-1120.

(2) Dhar, D. N. Chemistry of Chalcones and Related Compounds, Wiley, New York 1981.

(3) (a). Batt, D. G.; Goodman, R.; Jones, D. G.; Kerr, J. S.; Mantegna, L. R.; McAllister, C.; Newton, R. C.; Nurnberg, S.; Welch, P. K.; Covington, M. B. J. Med. Chem. 1993, 36, 1434-1442 and references therein. (b). Bowden, K.; Dal Pozzo, A.; Duah, C. K. J. Chem. Res, Synop. 1990, 12, 280130.

(4) For a comparison of spectroscopic data, refer to: Pouchert C. J.; Behnke, J. The Aldrich Library of ${ }^{13} \mathrm{C}$ and ${ }^{1} \mathrm{H}$ FT NMR Spectra, ed. I, 2, 875C.

(5) For a comparison of spectroscopic data, refer to: Le Roux, C.; Gaspard-Iloughmane, H.; Dubac, J. J. Org. Chem. 1994, 59, 2238-2240.

(6) Typical procedure: To an argon flushed solution of $\alpha$-bromostyrene $1 \mathbf{a}(0.5 \mathrm{mmol})$ and benzaldehyde $\mathbf{2 a}$ $(0.5 \mathrm{mmol})$ was added $\mathrm{BF}_{3} \cdot \mathrm{Et}_{2} \mathrm{O}(0.1 \mathrm{mmol})$ at r.t. and allowed to stir at this temperature for $24 \mathrm{~h}$. The reaction mixture was then quenched with water, extracted with $\mathrm{CH}_{2} \mathrm{Cl}_{2}(3 \times 25 \mathrm{~mL})$ and the combined organic layers were dried over $\mathrm{MgSO}_{4}$ and 
filtered. Concentration and purification by recrystallization $\left(\mathrm{CH}_{2} \mathrm{Cl}_{2} / \mathrm{n}\right.$-hexanes) gave the bromide intermediate $\mathbf{3 a}$, followed by silica gel chromatography and recycle preparatory HPLC for analytical purposes, to furnish transchalcone 4a. 3a: ${ }^{1} \mathrm{H}$ NMR $\left(300 \mathrm{MHz},\left[\mathrm{CDCl}_{3}\right], 25^{\circ} \mathrm{C}\right.$, TMS $)$ 7.94 (m, 2H, ArCH), 7.25-7.61 (m, 8H, ArCH), 5.67 (dd, $\left.{ }^{3} J(\mathrm{H}, \mathrm{H}) 7.9 \& 6.0 \mathrm{~Hz}, 1 \mathrm{H}, \mathrm{PhC}(\mathrm{I}) \mathrm{H}\right), 4.11\left(\mathrm{dd},{ }^{3} J(\mathrm{H}, \mathrm{H}) 17.5 \&\right.$ $8.1 \mathrm{~Hz}, 1 \mathrm{H}, \mathrm{C}(\mathrm{I}) \mathrm{CH}), 3.80\left(\mathrm{dd},{ }^{3} \mathrm{~J}(\mathrm{H}, \mathrm{H}) 17.5 \& 6.0 \mathrm{~Hz}, 1 \mathrm{H}\right.$, $\mathrm{C}(\mathrm{I}) \mathrm{CH}) ; \mathrm{MS}(70 \mathrm{~V}): \mathrm{m} / \mathrm{z}(\%): 290$ (3) [M+H], 105 (100) [ $\left.\mathrm{C}_{7} \mathrm{H}_{6} \mathrm{O}-\mathrm{H}\right]$; HRMS: Calcd. for $\mathrm{C}_{15} \mathrm{H}_{13} \mathrm{BrO}$ : 288.0150. Found: 288.0155; 4a: ${ }^{1} \mathrm{H}$ NMR $\left(300 \mathrm{MHz},\left[\mathrm{CDCl}_{3}\right], 25^{\circ} \mathrm{C}, \mathrm{TMS}\right)$ 7.94-8.20 (m, 1H, $\mathrm{ArCH})$, 7.65-7.79 (m, 1H, $\mathrm{ArCH}), 7.56-$ $7.65(\mathrm{~m}, 1 \mathrm{H}, \mathrm{ArCH}), 7.31-7.42(\mathrm{~m}, 9 \mathrm{H}, \mathrm{ArCH} \& \mathrm{CH}=\mathrm{CH})$; MS (70V): m/z (\%): 208 (100) [M·]; HRMS: Calcd. for $\mathrm{C}_{15} \mathrm{H}_{12} \mathrm{O}: 208.0888$. Found: 208.0890

(7) Lee, K; Wiemer, D. F. Tetrahedron Lett. 1993, 34, 2433-2436.

(8) Babler, J. H.; Invergo, B. J. Tetrahedron Lett. 1980, 22, 11-14.
(9) 4f: ${ }^{1} \mathrm{H}$ NMR (300 MHz, $\left.\left[\mathrm{CDCl}_{3}\right], 25{ }^{\circ} \mathrm{C}, \mathrm{TMS}\right) 7.87$ (d, $\left.{ }^{3} J(\mathrm{H}, \mathrm{H}) 8.3 \mathrm{~Hz}, 2 \mathrm{H}, \mathrm{ArCH}\right), 7.74\left(\mathrm{~d},{ }^{3} J(\mathrm{H}, \mathrm{H}) 15.7 \mathrm{~Hz}, 1 \mathrm{H}\right.$, $\mathrm{C}=\mathrm{CH}), 7.57\left(\mathrm{dd},{ }^{3} J(\mathrm{H}, \mathrm{H}) 6.0 \& 4.0 \mathrm{~Hz}, 2 \mathrm{H}, \mathrm{ArCH}\right), 7.47(\mathrm{~d}$, $\left.{ }^{3} J(\mathrm{H}, \mathrm{H}) 15.7 \mathrm{~Hz}, 1 \mathrm{H}, \mathrm{CH}=\mathrm{C}\right), 7.33\left(\mathrm{dd},{ }^{3} J(\mathrm{H}, \mathrm{H}) 5.6 \& 2.4 \mathrm{~Hz}\right.$, $3 \mathrm{H}, \mathrm{ArCH}), 7.23\left(\mathrm{~d},{ }^{3} \mathrm{~J}(\mathrm{H}, \mathrm{H}) 8.1 \mathrm{~Hz}, 2 \mathrm{H}, \mathrm{ArCH}\right), 2.36(\mathrm{~s}, 1 \mathrm{H}$, $\left.\mathrm{CH}_{3}\right)$; 4i: ${ }^{1} \mathrm{H} \mathrm{NMR}\left(300 \mathrm{MHz},\left[\mathrm{CDCl}_{3}\right], 25^{\circ} \mathrm{C}, \mathrm{TMS}\right) 7.92(\mathrm{~d}$, $\left.{ }^{3} J(\mathrm{H}, \mathrm{H}) 8.1 \mathrm{~Hz}, 2 \mathrm{H}, \mathrm{ArCH}\right), 7.61-7.65(\mathrm{~m}, 2 \mathrm{H}, \mathrm{ArCH}), 7.52(\mathrm{~s}$, $1 \mathrm{H}, \mathrm{CH}=\mathrm{C}), 7.38-7.41(\mathrm{~m}, 3 \mathrm{H}, \mathrm{ArCH}), 7.23-7.30(\mathrm{~m}, 2 \mathrm{H}$, $\mathrm{ArCH}), 2.42\left(\mathrm{~s}, 1 \mathrm{H}, \mathrm{CH}_{3}\right)$.

(10) For other examples of known reactions resulting in hydride extraction occurring from initial nucleophilic addition, refer to: (a). Ashby, E. C.; Coleman D.; Gamasa, M. J. Org. Chem. 1987, 52, 4079-4085. (b). Swain, C. G.; Powell, A. L.; Sheppard W. A.; Morgan, C. R. J. Am. Chem. Soc. 1979, 101, 3576-3583. (c). March, J. Advanced Organic Chemistry, John Wiley and Sons, New York 1992, 1235.

Article Identifier:

1437-2096,E;2001,0,SI,0910,0913,ftx,en;Y20400ST.pdf 